\title{
ANTECEDENTES Y MARCO TEÓRICO-JURÍDICO DE LA REFORMA ADMINISTRATIVA EN COSTA RICA
}

\author{
ROLANDO BOLAÑOS GARITA \\ Escuela de Ciencias de la Administración \\ Universidad Estatal a Distancia, Costa Rica \\ rbolanos@uned.ac.cr
}

\section{RESUMEN}

La concreción de acciones de reforma administrativa en Costa Rica conlleva a un análisis minucioso de elementos y actores de diverso tipo: doctrinarios, socioeconómicos, técnicos y jurídicos, nacionales e internacionales, los cuales se han entremezclado - y todavía lo hacen-, para conformar así todo un esquema de grandes proporciones sobre lo que ha sido el modelo de Estado costarricense, y en lo que puede convertirse. El reconocimiento de este esquema, que ostenta rasgos distintivos que no necesariamente encontramos en otros países, implica que las propuestas de reforma criolla sean precisamente eso: autóctonas, lo cual obliga a evitar por beneficio propio, la extrapolación de propuestas o tendencias foráneas que, a pesar de resultar en otras latitudes, es muy seguro que no apliquen para las dimensiones costarricenses.

PALABRAS CLAVE: MODELO DE ESTADO, REFORMA ADMINISTRATIVA, MIDEPLAN.

\section{ABSTRACT}

Administrative reform actions in Costa Rica involves a thorough analysis of elements and mixed actors of several kinds: doctrinal, socioeconomic, technical and legal, nationals and internationals, all this to conform a whole scheme of considerable proportions about what has been the Costa Rican State model, and about what it can become. The recognition of this scheme, which boasts distinctive features not necessarily found in other countries, implies that original reform proposals are just that: our own proposals; that means extrapolating trends or foreign approaches should be avoided, even when they have been successful, since, very positively, they will not apply to the Costa Rican dimensions.

KEY WORDS: GOVERNMENTAL MODEL, ADMINISTRATIVE REFORM, MIDEPLAN. 


\section{INTRODUCCIÓN}

El presente aporte ha sido considerado desde su título, como un aporte breve a una temática más que abundante, que ha sido abordada, enriquecida, y si se quiere, distorsionada por muchos. $Y$ es que tratar el tema en cuestión es posible desde diferentes campos epistemológicos, por ejemplo: desde las Ciencias Políticas, las Ciencias de la Administración, las Ciencias Jurídicas, etc. Valga aclarar también, que la reforma administrativa no es una temática exclusiva del aparato burocrático costarricense, sino que tiene alcances mundiales. Precisamente, dichos alcances han generado que en ocasiones las presiones por lograr un nuevo esquema estatal provengan del entorno; incluso, que se hable según Cunill (1999), Oszlack, (1999), Filgueira y Martínez (1998), de generaciones de reforma.

A pesar de lo anterior, la presente investigación se enfoca en lo relativo a Costa Rica, sin menosprecionar elementos contextuales. Esquematizada a partir del análisis documental, no pretende aglutinar todo lo que de este tema se ha escrito en el país, sino más bien abonar al debate temático, sin obviar lo que consideramos las bases políticas costarricenses más claras sobre reforma administrativa de los últimos 25 años.

Debe considerarse que la conformación del Estado costarricense no fue posible en un corto tiempo, sino que han pasado décadas para ello, aún y cuando esta germinación y consolidación venga acompañada de una hipertrofia en las articulaciones y líneas de dirección y comunicación entre Poderes del Estado, y más precisamente, entre las instituciones de la Administración Central y la Descentralizada.

Con base en lo anterior, pretender generar una propuesta sólida y coherente de reforma gubernativa y, más aún, lograrla con altos niveles de efectividad en un único periodo gubernativo, sería más que aventurado, ilusorio. Justamente, consideramos que ese es el punto medular para que otros intentos no hayan obtenido el éxito esperado y así hayan caído en el olvido, porque fueron intentos aislados, desarticulados de esfuerzos anteriores, sobre todo los bosquejados a partir de la Comisión de Reforma del Estado Costarricense (COREC) (1990).

\section{METODOLOGÍA}

El presente aporte investigativo es de naturaleza cualitativa-etnográfica, empleando como técnica principal el análisis documental.

El objetivo general se enfoca en "Determinar los elementos antecedentales, teóricos y jurídicos que facultan al Gobierno costarricense a generar propuestas modelísticas de reforma estatal, a fin de lograr el esclarecimiento de ese marco potestativo, el cual debe dedicarse de manera irrestricta al desarrollo nacional".

\section{RESULTADOS}

\section{Corrientes definitorias de una reforma}

En primera instancia, valga aclarar que, un movimiento de reforma estatal o administrativa criollo, no puede considerarse ajeno a las condiciones políticas del momento, específicamente a la coyuntura o ideología política que detente la presidencia del Poder Ejecutivo y del Poder Legislativo. Esto no podría ser de otra manera, ya que al primero, considerando la separación de poderes establecida por el Barón de Mothesquieu, le corresponde activar y dirigir los mecanismos a su alcance para lograr el desarrollo nacional, echando mano a los recursos humanos, técnicos y financieros de la Administración Central y la Descentralizada. 
Esa activación y dirección mencionadas son posibles a partir de los principios del proceso administrativo - dirección, planificación, organización, control y evaluación-, y es el primero de ellos, siguiendo la teoría de Meoño Segura (1986, 2005, 2008a, 2011 y 2012), el que otorga potestades al Presidente de la República para alinear el desempeño de todas las instituciones públicas bajo su alero, al efectivo cumplimiento del Plan Nacional de Desarrollo (PND), considerando materializar un Modelo-País que debe tomar forma a partir de lo prescrito en la Constitución Política, principalmente, de los artículos 46, 50 y 74 (Meoño, 2008b).

Si el gobierno de turno es de corte neoliberal ', es seguro que buscará un achicamiento del aparato estatal, considerando que su ideología, sobre todo por lo prescrito por Adam Smith y su mano invisible, promulga la no intervención estatal, salvo en aquellas actividades de máxima necesidad, ya que las fuerzas del mercado dictarán las condiciones socioeconómicas para la convivencia humana. Pero también otros teóricos han calado con fuerza en la opinión popular para así frenar el intervencionismo estatal en las actividades económicas, tal y como lo señala Guerrero (2010), al nombrar entre los potenciadores de esta corriente a Ludwing von Mises, Friedrich Hayek y Wálter Lippmann.

En la esquina contraria ubicamos a la socialdemocracia, corriente que propugna un papel estatal más vigoroso, concibiendo al Estado como responsable natural de aquellas acciones políticas, administrativas y económicas que se requieran para lograr un bienestar social; doctrina que por cierto encuentra reflejo en la llamada "economía del bienestar" (Aguilar, 2008). Su manifestación más preclara en el ámbito nacional

1 Como bien apunta el expresidente Miguel Ángel Podríguez refiriéndose al liberalismo, figura primigenia del neoliberalismo:" El liberalismo constituye una de las teorías que analizan cuáles deben ser los objetivos y la esfera de acción de los gobernantes..." (1985, p. 97) la encontramos en el artículo 50 constitucional, el cual establece en su primer párrafo que: "El Estado procurará el mayor bienestar a todos los habitantes del país, organizando y estimulando la producción y el más adecuado reparto de la riqueza."

Ahora bien, es importante considerar que lo plasmado en los artículos constitucionales de referencia no es un producto casuístico o improvisado, sino que es una herencia que podemos ubicarla desde los tiempos coloniales, y que termina implosionando durante la Asamblea Nacional Constituyente de 1949.

Sobre la dominancia que tuvo el colonialismo español para con el accionar administrativo de sus enclaves -y sus efectos aún visibles-, tanto los Stein (1974) como Meoño (1988), Araya (2006) y Naranjo (2010), lo alinean con la centralización que ejerció el regente español para con prácticamente todo lo que se refería a las tierras conquistadas: forma de organización (Virreinatos y Capitanías Generales), actividades económicas y repartición de terrenos, mecanismos de comunicación, etc. Dicha centralización la notamos en Costa Rica con claridad meridiana a partir del modelo político-administrativo vigente: el Presidencialismo, en contraposición con el Parlamentarismo más propio de naciones europeas, o incluso, con la organización federativa que presenta Estados Unidos de América.

Así las cosas, cuando se llega en 1949 a discutir el proyecto de Constitución Política presentado por la Junta Fundadora de la Segunda República, los vestigios del centralismo colonial resurgen y dan paso a nuestra actual Carta Magna, que a pesar de tener como base la Constitución de 1871, incluye artículos que permiten un mejor desempeño estatal en todos los ámbitos, artículos que se han visto complementados con normas de menor rango (leyes), que finalmente dan margen suficiente para una esquematización y un accionar burocrático-administrativo de 
grandes proporciones, sin necesidad de incurrir en el intervencionismo desmedido. No obstante, lo anterior nos ha servido para aclarar por qué, y desde qué momento se activa en el país el ánimo constante por formar y reformar un aparato público que, aparentemente, nunca ha satisfecho a los niveles políticos de Gobierno o de oposición. Sin dejar de mencionar a otros actores de corte profesional y académico que también se han referido a la necesidad de modelar algo nuevo y más vigoroso en materia de Administración Pública (UCR, 1996; PNUD-FLACSO, 2005).

A pesar de lo anterior, vale la pena un breve repaso de ciertas etapas históricas que han tenido sus propios principios ideológicos acerca de cómo debe modelarse el esquema burocráticoestatal. Tales etapas no pueden concebirse, ni medirse, como cortes transversales en el tiempo, iniciadas y cerradas bajo preceptos discursivos, normativos o técnicos tangibles. Igual aplica en el caso de querer ubicar a la llustración u otro movimiento transnacional de connotaciones filosóficas, políticas, socioculturales o económicas; debe realizarse un esfuerzo por mapear la serie de tendencias que permiten su ubicación temporal y geográfica.

\section{a. Estado Benefactor}

Esta etapa, según Pérez (2002), se ubica desde 1948 a 1980, teniendo como referente el auge en la producción y exportación del café, periodo al que pueden sumársele consideraciones geográfico-internacionales que marcaron en lo profundo la forma en que el aparato estatal debía hacerle frente a tales consideraciones, por ejemplo, el inicio de la guerra fría y la contraofensiva estadounidense a nivel latinoamericano (la estrategia de la Alianza para el Progreso y la conformación de la Organización de Estados Americanos), la activación del llamado Mercado Común Centroamericano, las crisis (cíclicas, según lo más ortodoxo de la teoría económica) en los precios del petróleo, etc.
Meoño (2011) también ubica su apogeo entre 1948-1980, lapso en el cual se crean 113 instituciones públicas, números estos que concuerdan con los provistos por Fallas (1982), quien aclara que en esta etapa el sector público asume un papel de estabilizador de la economía, ante los cambios que se dan en el ritmo de crecimiento de ésta.

Su decadencia la vislumbramos a partir de la década del ochenta, cuando las potencias occidentales -Estados Unidos e Inglaterra- ostentan gobernantes de marcado arraigo neoliberalista, y su ideología se desperdiga por todo el mundo, propulsada por el denominado Consenso de Washington. Dicha ideología tiene como brazos operativos al Fondo Monetario Internacional, al Banco Mundial² y a la Agencia Internacional para el Desarrollo (AID), con sus prescripciones sobre el libre mercado y la conceptualización del Estado como regulador de la empresa privada e impulsor del Libre Comercio, y como recetario común: los Programas de Ajuste Estructural (PAE), enfocados en gran parte a la racionalización y reducción de las instituciones públicas como mecanismo de contención del gasto público. Estaríamos en presencia de lo que la obra de Lizano (1987) considera como condicionalidad cruzada.

Más adelante se detallará cómo la AID ha tenido un arraigo más tangible en las acciones nacionales de reforma administrativa.

\section{b. Estado Empresario}

De la lectura a Quesada (2008), bien puede considerarse al Estado Empresario como un hijo legítimo del Estado Benefactor, ya que es durante este último cuando se gestan y fortalecen los

2 Por su parte, Zaki Laidi (citado por Sn Vestre Piam, 1994), indica que la vaguedad del concepto "ajuste estructural", no puede endilgársele al Banco Mundial, sino al Liberalismo histórico per se. Tal argumento no puede calificarse más que de contradictorio, ya que la misma entidad termina de accionar los mecanismos para implementar mundialmente los PAE, los cuales fueron argumentos clave de la corriente Neoliberal del periodo aquí analizado. 
principios doctrinarios y las condiciones sociopolíticas para aspirar a la idea de que el aparato estatal debe ramificarse de tal manera que impacte positivamente a la sociedad costarricense, incluso, desde la provisión, aunque sea momentánea, de servicios de consumo empresarial (cemento, fertilizantes, aluminio, etc.)

Recurriendo nuevamente a Pérez (2002), este ciclo del Estado se activa en 1972 con la constitución de la Corporación Costarricense de Desarrollo (CODESA), y se extiende con ciertas líneas de ferrocarril, la adquisición de la Refinadora Costarricense de Petróleo RECOPE, y la constitución de la entonces Asociación Bananera Nacional (ASBANA), por citar solo algunas.

Posteriormente, pueden ubicarse también dentro de este esquema a instituciones como el Instituto Costarricense de Electricidad (ICE), Correos de Costa Rica (antigua Dirección Nacional de Comunicaciones), Instituto Costarricense de Acueductos y Alcantarillados, etc., las cuales, si bien fueron creadas bajo la ideología de un estado proveedor de servicios bajo criterios de subsidio colectivo, para que así los servicios fueran accesados por la mayoría de la población, notará el lector que varias de ellas han sufrido cambios para competir ahora en una economía globalizada (tómese como ejemplo el caso del ICE, a partir de la ratificación del Tratado de Libre Comercio con Estados Unidos). Aún más, en otras latitudes, los servicios que algunas de estas brindan son de naturaleza eminentemente privada, tal y como en Argentina con la prestación de los servicios de electricidad y agua.

A la permanencia de algunas de las instituciones creadas durante el llamado Estado Empresario, debe sumársele lo establecido en el artículo 13 inciso p) del Código Municipal, que establece:

Artículo 13. Atribuciones del Consejo:

q) Constituir, por iniciativa del alcalde municipal, establecimientos públicos, empre- sas industriales y comerciales y autorizar la constitución de sociedades públicas de economía mixta...

Esta posibilidad de constituir sociedades públicas de economía mixta para mejor prestación de algunos de los servicios públicos brindados en las comunidades del país, tuvo mayor fundamento jurídico por medio de la Ley Reguladora de la actividad de las Sociedades Públicas de Economía Mixta 8828, que establece en su artículo 5 lo siguiente:

\section{Artículo 5.-Atribuciones}

Sin perjuicio de lo dispuesto en el artículo 2 de esta Ley, son atribuciones de las SPEM las siguientes:

a) Modernizar, racionalizar y ampliar los servicios públicos y las actividades productivas existentes.

b) Desarrollar nuevas actividades productivas, con el propósito de unificar integralmente los recursos humanos, naturales y de capital.

c) Promover el desarrollo humano integral.

Se excluyen de la aplicación de esta Ley los servicios públicos de acueductos y alcantarillado que seguirán prestándose como un servicio social sin fines de lucro, bajo el principio de servicio al costo.

No obstante lo anterior, el artículo 6 termina de sentar las bases para proyectos municipales de corte empresarial, prescribiendo lo siguiente:

Artículo 6.-Actividades mercantiles autorizadas.

Cada concejo determinará las actividades productivas a que se refieren los incisos a) y b) del artículo anterior, en razón de lo cual 
se tomará en consideración el aporte actual y potencial de dichas actividades, desde el punto de vista de la necesidad de:

a) Orientar y estimular la estructura productiva regional, proyectada a la comercialización nacional e internacional.

b) Fomentar y diversificar la comercialización nacional e internacional de bienes y servicios.

c) Integrar, de manera coordinada, los distintos sectores que componen el sistema económico regional, para aprovechar las oportunidades de desarrollo productivo, ambiental y humano.

d) Integrar el esfuerzo regional institucional del país a las políticas de las sociedades municipales de economía mixta.

e) Crear los mecanismos necesarios para la exportación de los productos que se dan en la región.

Por ende, se denota que la posibilidad no solo de mantener cierto esquema público de naturaleza empresarial, sino de aumentarlo, encuentra cabida a nivel de instancias descentralizadas administrativa o constitucionalmente, no así en la Administración Central o Poder Ejecutivo.

Llegados a este punto, es válido cuestionarse si el Estado, integralmente hablando, continúa o no en su etapa empresarial, aún y a pesar de la desaparición de CODESA y sus subsidiarias, principal exponente nacional del modelo de Estado Empresario. Nuestro criterio analítico al respecto es que, ciertamente, se ha dado una evolución acerca de aquello en lo que debe intervenir el Estado; pero no ha cesado, y se duda mucho de que algún día lo haga, de incursionar en actividades que algunos conciben característicamente de corte empresarial-privado.

\section{c. Estado Regulador}

A partir de la activación de los PAE, se instituye la normatividad de la reforma administrativa pública, tanto así que para 1989 se formaliza la COREC, considerando la experiencia que tuvieron los PAE I y || en el entorno nacional, en lo que se refería a modelización estatal, que según De la Cruz, Li Chen, Morales y Zamora (s.f.), conllevaba el fortalecimiento de la Autoridad Presupuestaria, CODESA, Ministerio de Planificación Nacional y Política Económica (MIDEPLAN) y la Caja Costarricense del Seguro Social (CCSS), entre otros.

La conformación de la COREC puede catalogarse como visionaria, en razón de lo que ocurriría en la década siguiente, al llegar al cenit las presiones internacionales de achicamiento estatal, que para el caso de Costa Rica tiene como rasgos característicos, producto del PAE III ${ }^{3}$, el cierre de CODESA y la venta de FERTICA y CEMPASA (se incluía la Fábrica Nacional de Licores, pero esta finalmente no fue vendida), la movilización laboral en el sector público mediante retiros voluntarios y jubilaciones adelantadas, por citar solo algunas 4 .

Es entonces cuando se habla del cambio paradigmático estatal, al pretender que este debe dejar de lado su papel intervencionista en la economía nacional mediante acciones y programas gubernativos que pueden considerarse propios del ámbito privado, evolucionando a un rol más

3 No es intención medular del presente ensayo un abordaje profuso sobre el PAE III al existir copiosa bibliografía al respecto; y sobre todo, se recomienda la consulta del expediente legislativo que devino, principal y primeramente, en la ley 7454.

4 Otras estipulaciones nacerían jurídicamente tiempo después, tal y como la Ley de Concesión de Obra Pública 7762, la ley de promoción de la competencia y defensa efectiva del consumidor 7472, la Ley para el régimen privado la pensiones complementarias 7523, la concreción de un programa de reforma presupuestaria para lograr un Sistema de Administración Financiera integrado -lo cual culmina con la aprobación de la Ley de Administración Financiera de la República y presupuestos públicos 8131, que por cierto no pudo cubrir a ciertas instituciones descentralizadas como la CCSS-; O incluso, el contar con una Ley de eficiencia tributaria, que se materializa con la Ley de simplificación y eficiencia tributaria 8114. 
de Estado-Gendarme, por así decirlo, con capacidades más reducidas, exclusivamente dirigido a proveer las macro actividades de interés nacional como la salud, la defensa nacional, etc., y regular las actividades públicas que no enturbien las relaciones económicas de la libre competencia entre los agentes económicos domésticos.

Una acepción que consideramos se yuxtapone con la noción de Estado Regulador, es la provista por el Banco Mundial (citado en Fonseca, 2001), indicando dicha entidad lo siguiente:

...Es el conjunto de medidas de supervisión y control de las actividades económicas de las empresas privadas y las empresas públicas independientes por parte de un gobierno, en aras de la eficiencia económica, la equidad, la salud pública y la seguridad. La regulación puede simplemente consistir en la promulgación de leyes, dejando que la supervisión corra a cargo de los procedimientos jurídicos normales, o bien ponerse en manos de organismos especiales establecidos con ese fin; también puede alentarse la autorregulación mediante reconocimiento de órganos voluntarios y, en algunos casis, la delegación de facultades en ellos (p. 87).

El culmen del concepto de Estado Regulador puede ubicarse a través de la corriente denominada Nueva Gerencia Pública (NGP), corriente esta que según Ferreiro (2009) fue inspirada en las prescripciones de la economía política neoclásica o escuela de Chicago, y por supuesto, en Milton Friedman. Tuvo posteriormente un salto exponencial durante la década del noventa, cuando llega a la palestra internacional la obra de Osborne y Gaebler, Reinventing Gobernment (1992), así como otras derivadas de la misma, tanto de carácter anglosajón: La reducción de la burocracia. Cinco estrategias para reinventar el gobierno, de Osborne y Plastrik (1998), como algunas propias de Latinoamérica: Una nueva gestión pública para América Latina, del Centro
Latinoamericano de Administración para el Desarrollo (CLAD) (1998).

Es esta etapa cuando se da un uso intensivo o abuso de consideraciones teóricas y conceptuales para, supuestamente, redefinir el rol del Estado, buscando transplantar a modo de recetario, las técnicas de gerenciamento privado hacia lo público. En otras palabras, se buscaba pasar a una era postburocrática, cayendo en el error de considerar seriamente los discursos en los que se pedía sustraer del aparato estatal cualquier indicio del esquema burocrático Weberiano.

Coyunturalmente, se pregonaba una redefinición de las relaciones Estado-Sociedad, en las cuales existiera en lo sucesivo un ciudadano-cliente, concepto este de corte mercantilista-consumista, valga resaltar. De igual manera, brillaban con luz propia consideraciones como: la rendición de cuentas por parte de los funcionarios públicos o accountability, la descentralización o desconcentración de los servicios, la tercerización de estos, la reingeniería de procesos, la separación entre acciones netamente políticas de las propiamente administrativas; en fin, todo un crisol de elementos nada nuevos, incluso algunos propios de la Administración Pública criolla. Otros, absolutamente falaces, tal y como la creencia de que lo administrativista y lo político se ubican en posiciones dicotómicas, distantes o antagónicas, casi irreconciliables.

\section{d. Otras formas de Estado}

Igualmente, podemos hallar figuras híbridas, tal y como lo extraemos de Zúñiga (2000), al referirse al Estado Concertador, concibiéndolo como: “... una nueva modalidad de intervención en la que, sobre la base del consenso nacional, el Estado no entorpezca la acción del sector privado, sino que la promueva con intervenciones globales para que sea éste, particularmente el sector exportador, el que se convierta en el eje del desarrollo nacional" (p.36). 
Zuñiga (2000) ubica por primera vez esta figura durante la primera administración Arias Sánchez, y posteriormente nota asomos en el Programa de Gobierno de la administración Figueres Olsen. Así, la intermitencia en la aparición de la misma, refuerza el apelativo que Zúñiga brinda al respecto, considerándola: “... un producto de la emergencia provocada por el colapso del intervencionismo estatal socialdemócrata" (p. 39). Según tales razonamientos, no es extraño que en lo futuro surjan nuevas figuras o concepciones de lo que debe ser el engranaje estatal, utilizando esta expresión para evitar apuntar directamente a un tipo de ente público, ya que la conceptualización del Estado en sus diferentes formas (benefactor, empresario o regulador) puede abarcar la totalidad del esquema político-administrativo (Poder Ejecutivo, Legislativo, Judicial, Tribunal Electoral, Gobiernos Municipales o Instituciones Descentralizadas), o bien puede dedicarse a la mutabilidad o modernización solo de una parte del mismo.

Llegados a este punto, reiteramos el detalle introductorio del presente apartado: no resulta tan sencillo ubicar un tipo de esquema de organización estatal en las corrientes del tiempo, ya que más bien las connotaciones filosóficas, políticas, socioculturales o económicas del momento, empujan a una imbricación constante entre un esquema y otro. Sería engañoso marcar un punto de inicio y término para los diversos modelos filosóficos del Estado; eso sería aparte de extremista, fútil; tales esquemas no son piezas mecánicas que embonan a la perfección o que se remuevan al antojo del conductor político. Más bien, resultan mutatis mutandis.

\section{CONSIDERACIONES TERMINOLÓGICAS}

Previo a ahondar en mayores detalles, resulta indispensable aclarar si el radio de acción de una reforma de lo público comprende el concepto Estado en términos holísticos, o bien, si solo se circunscribe a la expresión orgánico-funcional central de éste, o sea, la Administración Pública a nivel Central y Descentralizada, también concebida con el término Gobierno. Se puntualizan entonces detalles terminológicos de interés al respecto.

\section{ESTADO / GOBIERNO}

Porrúa (citado por Jiménez Castro, 1986) aclara los alcances del Estado de la siguiente manera:

En el lenguaje vulgar se confunden Estado y Gobierno... [aunque] podemos afirmar que no son términos equivalentes. La palabra "Estado" designa la organización política en su conjunto, en su completa unidad formado por los diversos elementos que la constituyen. "Gobierno" se utiliza para designar el conjunto de poderes públicos, de los órganos a quienes se atribuye el ejercicio supremo de la soberanía. Entonces, el Estado es en un concepto más amplio, abarca el todo. El Gobierno únicamente se refiere a uno de sus elementos, el que tiene la dirección misma del Estado. (p. 23)

Lejos de querer entonces entrar en valoraciones sobre los alcances de los términos Estado-Nación o Estado-Persona, valga por ahora limitarnos a aclarar que al referirse al ámbito que comprende una reforma pública, ésta tiene como foco de atención al Gobierno, en cualquiera de los Poderes en que se encuentra dividido, tal y como prescribe el párrafo primero del artículo 9 Constitucional: "El Gobierno de la República es popular y representativo, alternativo y responsable. Lo ejercen tres Poderes distintos e independientes entre sí: Legislativo, Ejecutivo y Judicial."

\section{REFORMA DEL ESTADO/ REFORMA ADMINISTRATIVA}

Basados en lo anterior, podrá vislumbrarse que no resulta antojadizo presentar una separación terminológica que aclare hasta dónde pueden o 
deben llegar los esfuerzos del ápice gubernativo por lograr un golpe de timón en el accionar del aparato estatal. En esta misma línea, Jiménez Castro presenta una división que consideramos dicotómica sobre reforma del Estado y reforma administrativa, indicando sobre el primero de ellos lo siguiente:

...cualquier Reforma del Estado debería comprender los cuatro aspectos existenciales [pueblo, territorio, poder organizado y soberanía] de manera que en el cambio necesario se involucre a la población para que fortalezca su capacidad de participación, y sea actora y no simple espectadora del proceso de transformación; exista incorporación de todo el territorio, de manera que aquellas áreas marginadas dejen de serlo y participen plenamente en los beneficios del desarrollo; se reestructure el ejercicio del poder, transformando obsoletas estructuras, relaciones, actitudes; y se fortalezca la soberanía en sus dos vertientes: nacional e internacional (2006, p. 88-89).

Nótese que al valorar el término Reforma del Estado, se estaría hablando de un proceso de amplio espectro, con capacidades extensas, más allá de un mero cambio en la estructura orgánico-funcional de las instituciones públicas, pudiendo, sí así lo permiten las condiciones políticas, sociales y económicas del momento, llegar hasta las bases fundacionales de la República. No se trata exclusivamente de consideraciones sobre la cantidad y conformación de los entes ministeriales, o sobre el desarrollo de acciones para paliar la estática ${ }^{5}$ en ellos, sino que una reforma

5 Este término, sumado al de entropía, los consideramos como los responsables naturales de aletargar a las organizaciones, potenciar su anacronismo y consiguiente desgaste y desfase para con las responsabilidades a ellas asignadas. Sobre estática, menciona Leemans: "Todos los sistemas organizacionales tienen un proceso interno de retroalimentación interno-negativa que propende a mantener constante un cierto estado o propiedad del sistema. Cierto grado de estática se vuelve, por tanto, inherente a cualquier organización" (1977, p.21-22). de este tipo incluye dentro de sus posibilidades, modificaciones a la Constitución Política, a las relaciones entre los Poderes Públicos (verbigracia, el expediente legislativo 17.743 "Ley de reforma de la Jurisdicción Constitucional"), por ejemplo.

Para mayor aclaración, presentamos lo prescrito al respecto por la COREC, al indicar:

La reforma del Estado es global, aunque para poder ejecutarla debe tener también un enfoque selectivo de acuerdo con las prioridades que las autoridades y la misma sociedad considera como más importantes de alcanzar. Demanda estrategias para modificar aspectos estructurales, en tanto que la Reforma Administrativa es más de naturaleza coyuntural; pero ambas se complementan y deben, por tanto estar estrechamente vinculadas para evitar esfuerzos descoordinados (1990, p. 145).

Concatenado a lo hasta aquí expuesto, ubicamos lo señalado entonces por Campero (1982), que también resulta de medular importancia para determinar un posible antagonismo entre los términos analizados; indica el autor:

En los últimos años, algunos países de América Latina ha sustituido el concepto de reforma administrativa por los de planificación, desarrollo o modernización de la administración pública, para significar que la acción reformadora ha pasado de ser un fin en sí misma a ser un valioso elemento del desarrollo nacional (p. 12).

Y, más adelante, en forma contundente, remacha con la siguiente consideración:

La planificación administrativa, al integrar el esfuerzo de reforma administrativa con los planes globales de desarrollo, hace que en América Latina la reforma adquiera bajo esa filosofía una nueva razón de ser y su utilidad es claramente comprendida. En efecto, "...la 
transformación de las estructuras, sistemas y procedimientos de la administración pública tienen ahora una nueva justificación y una nueva ética: la de lograr que esas estructuras sistemas y procedimientos permitan el desarrollo, o más precisamente, permitan la ejecución de los planes de desarrollo económico y social y no se convierta en su freno" (p. 15)

Los argumentos transcritos se acoplan, en nuestro criterio, perfectamente a la intencionalidad de la Ley de Planificación Nacional 5525, y a su ámbito de acción en materia de modernización pública, específicamente por medio de sus artículos 16, 17 y 18. Entonces, bien podemos afirmar que Costa Rica se encuentra en un esfuerzo permanente de reforma nacional por medio de MIDEPLAN, según el marco de acción de éste, mismo que se aclara en líneas posteriores.

Por lo tanto, debe quedar atrás la visión anacrónica, obsoleta y polarizada de que la reforma administrativa tiene como objetivo principal la promulgación de leyes sobre la esquematización del sector público, esto en un concepto macroadministrativo; o bien que se ubica en el otro extremo, el micro administrativo, concibiendo sobre todo cambios en los organigramas de las instituciones (en forma desperdigada y nada sistémica) y en la generación de Manuales de Procedimientos. Porque como bien señaló en su momento Gonzalo Martner:

En realidad, un proceso de reforma administrativa podría iniciarse en esa forma, pero su objetivo final no se cumple por decreto, sino través de un proceso de cambios que lleva a una transformación en el proceso social y económico, modifica las relaciones sociales y el comportamiento de organismos, personal y dirigentes (1975, p. 172)

Ergo, siempre resulta inexorable aterrizar primero en el diferenciamiento terminológico para posteriormente activar lo metodológico en cuanto a reforma se refiere, ya que según las acepciones transcritas, Reforma del Estado y Reforma Administrativa no pueden considerarse enteramente sinónimos, cuando el primero atañe a un esfuerzo de proporciones nacionales, que incluyen, según lo considerado por Jiménez Castro, elementos de soberanía. En su defecto, el segundo término, valiéndonos de lo prescrito por Campero, resulta de menores proporciones, más dirigida al desarrollo nacional vía Plan Nacional de Desarrollo. Pero tampoco puede considerarse que tales términos estén enfrentados o en posible antagonismo, porque como bien acotó la COREC, son complementarios.

\section{REORGANIZACIÓN O REESTRUCTURACIÓN}

En el acápite anterior pudo demostrarse que las diferencias terminológicas pueden conllevar también a diferencias en los alcances de los fenómenos que impactan en el andamiaje administrativo público. Bajo ese prisma, se considera indubitable entrar a considerar si al hablar de Reforma Administrativa esta implícitamente tiene como efecto directo una reorganización o una reestructuración, por cuanto tales términos tampoco pueden considerarse homólogos, como tampoco sus efectos administrativos.

Previamente (Bolaños, 2010a), nos referimos al trato diferenciado que debe dársele a ambos términos, muy a pesar de que entes judiciales, administrativos y fiscalizadores los conciban como sinónimos, refiriéndonos a la Sala Constituciona del Poder Judicial, a la Procuraduría General de la República y a la Contraloría General de la República, respectivamente.

$Y$ es que, consultada una serie de normas de rango constitucional, legal (leyes) y técnico (decretos ejecutivos), se llegó a la conclusión que el término no ideal, pero sí revestido de mayor integralidad, era precisamente Reorganización, considerando que éste incluso sería un nuevo intento de consolidar el Principio Administrativo 
de Organización; salvo que en este nuevo intento organizativo han mediado consideraciones de orden político-social, jurídicas, técnico-administrativas o presupuestarias que impulsan $u$ obligan a un reposicionamiento de una dependencia administrativa, o a varias de ellas. Su objetivo sería, en un afán de adaptabilidad y modernización, transformar los elementos que la conforman: estructura orgánica u organigrama, procesos administrativos internos, normativa interna, sistemas tecnológicos, ambiente organizacional o talento humano.

En su defecto, Reestructuración atañe a una circunscripción menor, exclusivamente dirigida al elemento estructural u organigrama.

\section{¿EL POR QUÉ Y CÓMO DE LA REFORMA ADMINISTRATIVA?}

Lo medular de cualquier ente público, y su eventual reforma, debe ser la adecuada prestación del servicio público ${ }^{6}$ que brinda a la ciudadanía. Bajo ese precepto, debe volverse la mirada al artículo 192 constitucional, que permite el cese o despido de funcionarios públicos cuando medie la reducción forzosa de servicios, ya sea por falta de recursos económicos para sufragar el pago de salarios, o para conseguir una mejor organización de dichos servicios públicos.

En dicho artículo confluyen precisamente las dos interrogantes que titulan este apartado: se enuncia cuál debe ser el objeto de la reforma administrativa -los servicios públicos-, y cómo puede ello lograrse -echando mano al Principio Administrativo de Organización-.

6 Algunas normas que abonan a la regulación del servicio público dentro de los límites de legalidad y la probidad serían: la Ley General de Control Interno 8292 y la Ley contra la corrupción y el enriquecimiento ilícito en la función pública 8422.

\section{EL SERVICIO PÚBLICO}

Con mayor grado de especificidad, la primera parte de la pregunta que titula este apartado la ubicamos en el artículo 4 de la Ley General de la Administración Pública 6227, que prescribe:

Artículo 4.- La actividad de los entes públicos deberá estar sujeta en su conjunto a los principios fundamentales del servicio público, para asegurar su continuidad, su eficiencia, su adaptación a todo cambio en el régimen legal o en la necesidad social que satisfacen y la igualdad en el trato de los destinatarios, usuarios o beneficiarios.

La noción de servicio público puede rastrearse desde la publicación del jurista nacional Romero Pérez (1983), quien señala: "La idea que se ha venido a presentar es la de que el servicio público es una institución, un régimen: la aplicación del derecho público a ciertos actos, ya sean ellos cumplidos en el marco de los organismos administrativos o fuera de ellos" (p.15).

En esa misma obra el autor aclara que la tesis que aplica es la del fin público, o sea, que el servicio público va encaminado al interés general, pudiendo ubicar una diferenciación entre los servicios públicos administrativos, y los servicios públicos industriales y comerciales.

Bajo esa tesitura, debería distinguirse en la praxis administrativa pública, una dicotonomía muy clara en cuanto a la prestación de los servicios públicos, pudiendo, según lo indicado por Romero, encasillarlos en dos categorías. Por el contrario, el asunto no termina de ser tan sencillo, ya que desde la óptica de la prestación encontramos otras formas más complejas, incluso hibridas. Por ejemplo, el mismo Romero se refiere a la posibilidad de admitir servicios públicos bajo el régimen del derecho privado, que denomina "de gestión privada". 
Precisamente, esa huida de la Administración Pública hacia el derecho privado, así nombraba tanto por ese autor (1983 y 2010) como por Cervantes (2000), la ubicamos en la gama de normas que se han incorporado al andamiaje jurídico-administrativo costarricense, verbigracia: la ley de sociedades anónimas laborales 7407, la ley marco para la transformación institucional y reformas de la ley de anónimas laborales $7668^{7}$ y su Reglamento, Decreto Ejecutivo 26893-MTSSPLAN; así como en la misma ley de contratación administrativa 7494 y su Reglamento.

El párrafo inmediato anterior se refiere a los servicios industriales y comerciales indicados por Romero Pérez, pero en lo tocante a los servicios administrativos, catalogados como aquellos por los que no se recibe una contraprestación, sino un esfuerzo (físico o mental) más propio de un funcionario público, entonces encontramos un verdadero crisol de posibilidades, ya que si bien el artículo 111 de la de la Ley General de la Administración Pública 6227 define al funcionario público, e incluso homóloga los términos "funcionario público", "servidor público", "empleado público" y "encargado de servicio público", el asunto toma otras proporciones al valorar lo establecido la Procuraduría General en el Dictamen C-256-2014, advirtiendo que para determinar si se es o no funcionario público, dependerá enteramente de las labores que realiza,

7 La opinión jurídica de la Procuraduría General, O.J.-146-2003, se refirió al entonces expediente legislativo 14.255, concluyendo que: "...es posible gestionar los servicios públicos de salud de atención integral en el ámbito hospitalario por privados..."

Por lo tanto, el autor de este artículo es del criterio de que si la prestación de servicios esenciales como los de la salud son posibles de brindar mediante la contratación de entes privados, entonces otra gama de servicios también lo son. Empero, las capacidades administrativas de los entes contratantes debe aumentar en iguales términos, a fin de lograr las mejores condiciones de selección, regulación y evaluación de tales servicios; de lo contrario, nos encontraríamos en una condición de posible menoscabo y de quebranto del interés general por el cual se contrataron. El asunto no puede limitarse al mero hecho de generar un cartel de contratación administrativa, sino a una valoración completa de la eficiencia y eficacia de lo que se presta a la ciudadanía. y la supeditación de las mismas a actuaciones administrativas "...cuyo resultado sea la alteración, creación y supresión de relaciones jurídicas administrativas con los administrados o con el resto de los servidores de la institución, actuaciones que pueden ser de fiscalización (como los desempeñados para resguardar el patrimonio de la institución o los efectuados por los auditores institucionales), de dirección (como la emisión de directrices, instrucciones, o el ejercicio de la potestad disciplinaria) o de servicio público, entre otros."

Así las cosas, corresponderá a cada institución, sobre todo las enmarcadas en un régimen de empleo mixto según la Procuraduría, las que deban analizar si un determinado funcionario debe tratarse como tal.

Lo anteriormente indicado y transcrito nos resulta útil para evidenciar dos aspectos medulares y consustanciales para lograr un mejor entendimiento de lo que es o no un servicio público: a) qué se presta y b) quién y cómo lo presta, a lo cual también debe agregársele el tamiz provisto por la Procuraduría General en su Dictamen C-152-2000 según Higaldo (2008):

En síntesis, el concepto de servicio público presenta las siguientes características:

- La actividad es de interés general.

- Interés general que se manifiesta en el carácter esencial de la actividad para el desenvolvimiento del Estado o porque satisface un interés o necesidad colectiva.

- La declaración de una actividad como servicio público determina que ésta es de naturaleza pública. La titularidad del servicio público corresponde a una Administración Pública, lo que se justifica por el interés público presente en la actividad y porque es la Administración Pública la encargada de tutelar ese interés público. 
- Los particulares requieren de una habilitación especial de la Administración titular para poder gestionar la prestación del servicio público. Por ende, puede haber un 'desdoblamiento' entre titularidad y gestión, en especial cuando se trata de servicios industriales y comerciales.

- La Administración titular conserva siempre determinados poderes respecto de la prestación del servicio, aun cuando éste sea explotado por particulares.

- La prestación en que consiste el servicio debe estar destinada a satisfacer necesidades de los usuarios (dictamen C-009-2000 del 26 de enero del 2000).

En esa misma obra, el autor (p. 72-74) remata prescribiendo que dentro de una perspectiva costarricense, la delimitación de la noción de servicio público lo permitirá el análisis de los siguientes factores:

- La naturaleza de la actividad

- El sujeto que la presta

- El fin perseguido

- Relación jurídico-pública

- Competencia

- La regulación

Pero, valga aclarar que en el momento de considerar una reforma de los servicios públicos, esta debe ajustarse a los términos eficiencia y eficacia.

Al hablar de eficiencia y eficacia como filtros para mejor valoración de programas y acciones públicas como herramienta para el desarrollo integral del país, debe consultarse la acepción que sobre estos brinda el autor costarricense Johnny Meoño Segura, en su obra Introducción al análisis de la burocracia pública (1980). En ella, el autor aclara que la eficiencia y la eficacia pública no pueden ser medidas en términos idénticos a la gestión privada. Por ejemplo, un programa de ayuda social como comedores escolares, becas estudiantiles o una calle cantonal, podrán no ser eficaces en términos de resarcimiento de costos. Incluso, podrían considerarse un gasto irrecuperable para el Gobierno; no obstante, en términos de la responsabilidad social del Estado como salvaguarda de las clases sociales vulnerables y de los derechos de los habitantes de la República, dichas acciones le son irrenunciables, lo cual no significa que deban darse sin controles, y por el contrario incurrir en el despilfarro. Así, a pesar de su irrecuperabilidad económica directa, por decirlo de algún modo comprensible, los programas antes mencionados no son eficientes, pero sí eficaces cuando llegan a la población indicada.

\section{LA ORGANIZACIÓN ADMINISTRATIVA}

La organización administrativa, como función propia del proceso administrativo, conlleva una constante valoración de elementos internos y externos, tal y como se indicó supra, en el apartado tocante al término Reorganización. En esta línea, considérese lo indicado por la Procuraduría General de la República en su Dictamen C-0842006, que en lo que nos interesa señala:

a) Las Administraciones Públicas (ministerios e instituciones), en ejercicio de su potestad de autoorganización, están facultadas para disponer la reestructuración administrativa de las diversas dependencias que las componen, con el fin de alcanzar su mejor desempeño y organización, para lo cual pueden disponer, a través de los procesos de reorganización o reestructuración interna, el establecimiento de nuevos órganos o una distribución interna de competencias que no impliquen potestades de imperio.

b) Corresponde a los jerarcas de los distintos ministerios e instituciones públicas determinar cuál es la organización más adecuada, en razón de los fines que deben cumplir. Sin embargo, el ejercicio de dicha competencia 
no es irrestricto sino que, por el contrario, se encuentra sometido a una serie de regulaciones y requisitos dispuestos por el propio ordenamiento jurídico.

c) Y, precisamente, una de las regulaciones o requisitos para el ejercicio de la potestad de reorganización administrativa, lo constituye la aprobación previa por parte del MIDEPLAN. En efecto, distintas disposiciones contendidas en la Ley de Planificación Nacional 5525 del 2 de mayo de 1974, le confieren a dicho Ministerio una serie de atribuciones en materia de planificación nacional, la cual incluye dentro del concepto de mejoramiento de la Administración Pública, lo concerniente a la reorganización interna de los ministerios e instituciones públicas.

A pesar de que en ese Dictamen el ente técnicoasesor del Estado incurre en la homologación de términos como reorganización y reestructuración, resulta de gran utilidad para comprender dos aspectos fundamentales: 1) los entes públicos gozan de una potestad de autoorganización para así alcanzar un mejor desempeño en la prestación de los servicios que brindan, 2) el MIDEPLAN aparece como organismo regulador, catalizador y dinamizador de esfuerzos de organización pública, con fundamento en la Ley de Planificación Nacional 5525.

Por otro lado, la capacidad de autoorganización, según consideraciones jurídicas, Ernesto Jinesta (2002) la alinea para el Poder Ejecutivo con el artículo 140, inciso 18 de la Constitución Política; para el Poder Legislativo con el artículo 121, inciso 22 de la misma Carta Magna. Para las instituciones descentralizadas nos refiere al artículo 103, párrafo primero de la Ley General de la Administración Pública 6227.

Independientemente de la naturaleza jurídica del organismo que ejercite la autoorganización, el autor señala que esto será posible mediante la emisión de un Reglamento Autónomo de
Servicio; tanto así, que acusa de inconstitucionales las leyes orgánicas de ministerios que regulan su organización, competencias internas o la distribución de éstas (p.166).

No obstante lo anterior, es importante reiterar que el diseño estructural de los entes públicos sujetos a la dirección gubernativa del Poder Ejecutivo es una responsabilidad compartida entre el respectivo jerarca y MIDEPLAN, según lo arriba indicado. Por lo tanto, según nuestro criterio analítico, lo adecuado sería primero tramitar ante ese Ministerio la aprobación de una reorganización administrativa (estructural y funcional), y posteriormente legalizarla vía Reglamento Autónomo. Esto por cuanto no sería dable legalizar lo aún no formado, o reformado. Se concluye así que el ejercicio y materialización del Principio Administrativo de Organización, a nivel de la Administración Pública costarricense, implica echar mano a razonamientos y recursos tanto técnico-organizacionales, como jurídico-organizacionales.

\section{LOS ACTORES INTERVINIENTES DE LA REFORMA}

La reforma administrativa pública ha sido una temática cuasi-exclusiva del Poder Ejecutivo, el cual, considerando el sistema político imperante en el país (presidencialismo) encuentra resonancia en el Poder Legislativo y en las instituciones descentralizadas creadas al amparo de los artículos 188 y 189 constitucionales. Dicho ámbito puede ampliarse al Poder Judicial, al Tribunal Supremo de Elecciones o a las Municipalidades, en el tanto la Asamblea Legislativa secunde y apruebe los proyectos que sobre estos le presente el Ejecutivo.

Esta cuasi-exclusividad se palpa en los amagos de reforma estatal integral surgidos a partir del punto álgido del Estado benefactor, periodo que es ubicable a nivel nacional más puntualmente durante la administración Monge Álvarez, 
suscribiéndose el primer PAE. Esa tendencia continúa durante la administración Arias Sánchez, misma que convoca a la COREC; así como en las administraciones Calderón Fournier, quien nombra al primer Ministro de Reforma del Estado; y Figueres Olsen, que nombra al último Ministro de Reforma del Estado conocido dentro del engranaje burocrático.

Como se indicó previamente, la confluencia de organismos financieros internacionales devino en los primeros intentos de reforma estatal, dentro de los que cobra gran protagonismo la AID -USAID en inglés-. El marco jurídico para la relación, aparentemente binómica, Gobierno-AID, se materializa en la ley 3011, encontrando reflejo posterior en una serie de Decretos Ejecutivos, siendo el último de ellos el 31587-H-PLAN, estableciendo en su artículo 1 la creación de "la Comisión Presidencial (COPRE) encargada de coordinar la definición de políticas generales de reforma institucional y reestructuración del Estado, así como los demás proyectos específicos de prioridad y beneficio para el Estado Costarricense, que se financien por medio de la Fundación de Cooperación Estatal (FUCE)."

Puede apreciarse que la AID ha servido de puente entre Costa Rica y EEUU para la concreción de acciones de aparente potenciamiento estatal desde 1962, alargándose el lazo por varios lustros más, por ejemplo, mediante acuerdos de donación y empréstitos (Villasuso, 2000). Y por supuesto, estuvo presente en los movimientos de reforma estatal de amplio espectro, ubicables en las décadas del ochenta y noventa (Rojas, 1987; Harrison, Lizano, Urcuyo \& Camacho, 1994), aportando millones de dólares para lograr la reconversión estatal.

Sin embargo, muy a pesar de que la AID haya tenido participación financiera o instrumental en la reforma estatal costarricense, no debe perderse de vista que siempre ha sido MIDEPLAN el organismo del Poder Ejecutivo con facultades y potestades suficientes para dinamizar y dictaminar cualquier macro o micro proceso de reforma, sea en la modificación de todo el aparato orgánico-funcional actual, o incluso en el análisis de proyectos de ley atinentes a la organización administrativa pública, según se desprende del Informe DFOE-SAF-01-2006, de la Contraloría General de la República. Esta es una perogrullada, aun y a pesar de que el mismo informe señale las omisiones en que ha incurrido MIDEPLAN para con sus deberes y facultades jurídico-técnicas.

Y es que al pasar revista a la gama de normas que facultan y obligan a MIDEPLAN a lo anterior, las potestades del MIDEPLAN se detallan en la Tabla 1.

TABLA 1

\section{DETALLE DE LAS POTESTADES DE MIDEPLAN PARA LA REFORMA ADMINISTRATIVA}

\begin{tabular}{|l|l|}
\hline \multicolumn{1}{|c|}{ NORMA/ÓRGANO EMISOR } & \multicolumn{1}{c|}{$\begin{array}{c}\text { ARTÍCULO/ } \\
\text { DOCUMENTO }\end{array}$} \\
\hline $\begin{array}{l}\text { Ley de Planificación Nacional 5525 } \\
\text { Ley reguladora del Sistema Nacional de Contra- } \\
\text { lorías de Servicio }\end{array}$ & $\begin{array}{l}\text { Artículos 16, 17 } \\
\text { y } 18 .\end{array}$ \\
\hline $\begin{array}{l}\text { Reglamento General de MIDEPLAN, Decreto } \\
\text { Ejecutivo 23323-PLAN }\end{array}$ & $\begin{array}{l}\text { Artículos 13 incisos } \\
\text { a), b), d) y e); y 15. }\end{array}$ \\
\hline $\begin{array}{l}\text { Reglamento a la Ley Marco para la transforma- } \\
\text { ción institucional y reforma de Ley de Socie- } \\
\text { dades Anónimas Laborales, Decreto Ejecutivo } \\
\text { 26893-MTSS-PLAN }\end{array}$ & Artículo 2. \\
\hline $\begin{array}{l}\text { Reglamento de creación de la Comisión Presiden- } \\
\text { cial (COPRE), Decreto Ejecutivo 31587-P-PLAN. }\end{array}$ & Artículo 3. \\
\hline $\begin{array}{l}\text { Reglamento General del Sistema Nacional de } \\
\text { Planificación, Decreto Ejecutivo 37735-PLAN }\end{array}$ & $\begin{array}{l}\text { Artículos 23, 38 } \\
\text { y 41 }\end{array}$ \\
\hline
\end{tabular}

Fuente: elaboración propia.

Toda esta panoplia técnico-jurídica resulta de gran valía no para presentar extractos normativos a diestra y siniestra, sino para demostrar fácticamente que las capacidades de MIDEPLAN para la mejor organización del aparato estatal son un hecho, y no meras especulaciones. También 
para demostrar que las consideraciones sociopolíticas del momento derivaron en las normas precitadas, y ahora sirven de bastión para que ese ente ministerial concrete acciones de amplio espectro referentes a adaptabilidad y modernización de las instituciones públicas, conforme los retos nacionales e internacionales del momento.

Valga indicar que la sola trascripción del articulado anterior carece de aplicabilidad e importancia cuando no se aborda al unísono, y peor aún, cuando no se comprende o se ejercita adecuadamente. Esto, mediante la capacidad técnica del propio MIDEPLAN al respecto. Justamente, esa capacidad subyace en dos posiciones muy claras: a) a lo interno del ministerio por medio de su actual Área de Modernización del Estado y b) a través de la Comisión de Eficiencia Administrativa (CEA). Por lo que si ambas no funcionan de manera simbiótica, considerando a la primera como la Secretaría Técnica del órgano colegiado (en otras palabras, la instancia técnica que cuenta con el personal suficiente y capacitado para esquematizar programas coherentes de reforma administrativa) nos podríamos encontrar con inconvenientes como propuestas de reforma con ciertas características: desperdigadas y desarticuladas entre sí, carentes de racionalidad técnica y empuje político, sin recursos humanos y financieros suficientes y sobrepasando la capacidad estatal para lograrlas, sobredimensionamiento estatal o por el contrario un enflaquecimiento a ultranza de este, esquematizaciones públicas sin apego a la normativa estructural vigente ${ }^{8}$, por mencionar solo algunas.

Ese rol de conductor hacia la modernización estatal que ostenta el Poder Ejecutivo, puntualmente por medio de MIDEPLAN, también fue motivo de análisis por la Contraloría General de la República en el Informe DFOE-SAF-01-2006, y en el cual se

8 En este sentido puede consultarse nuestro anterior artículo: Algunas consideraciones teórico-jurídicas para el diseño organizacional en la Administración Central costarricense (2010b). evidencian algunas holguras sobre la labor encomendada a ese poder de la República, incurriendo hasta la fecha, en un déficit de acciones más tangibles sobre reforma integral costarricense. Porque si bien rescatamos la valía de los instrumentos generados por el Área de Modernización del Estado, tal y como las guías, manuales y lineamientos sobre reforma administrativa, consideramos que tales instrumentos no son suficientes si no se engarzan con un programa plurianual de reforma que nazca a partir del Plan Nacional de Desarrollo del momento; pero, con miras a sobrepasar el tiempo limitado de cuatro años.

En este punto somos enfáticos: considerar que en un documento denominado Plan Estratégico Nacional se puedan plasmar acciones de reforma de largo plazo es caer en la ingenuidad técnica y política, por cuanto este instrumento no es obligatorio en cuanto a cambios de Gobierno se refiere, por lo que el gobernante de turno puede o no considerarlo vinculante, o bien, modificarlo según la visión partidista que predomine. Ciertamente, cualquier propuesta de corto o largo plazo está sujeta a estas visiones. Por lo que debe revalorarse la coyuntura existente en el corto periodo 1989-1991, en el cual la COREC, y posteriormente el primer ministro de Reforma del Estado, impulsaron propuestas muy claras sobre cómo conducir dichas propuestas, y los productos que de ellas devinieran.

Valga aclarar que un estudio de lo originado en ese periodo y contrastado con lo producido en otros, por ejemplo, en tiempos de la llamada COREC $\|$, de la Comisión de Eficiencia Administrativa y Reforma del Estado (CEARE) o de la actual CEA, sobrepasan los límites del presente aporte, dirigidos más bien a orientar al lector sobre los antecedentes y el encuadre de la reforma administrativa criolla, conciliando en el proceso, una serie de perspectivas que previamente aparecen disgregadas, absteniéndonos por ahora de presentar los resultados infructuosos o no de las acciones gubernativas al respecto. 
Tal comparación es objetivo de otro documento que se hermana con el actual.

Basta por ahora concretar en que la normativa vigente, la jurisprudencia judicial (Sentencias 3288-94 y 13660-2004 de la Sala Constitucional del Poder Judicial) y administrativa (Dictámenes C-084-2006 y C-070-2007), así como los informes de fiscalización sobre la Hacienda Pública (DFOESAF-01-2006), apoyan en demasía las potestades y responsabilidades del Poder Ejecutivo para conducir hacia el mejoramiento del esquema burocrático-institucional costarricense, el cual, bajo nuestra óptica, jamás deberá desprenderse del fin último para la existencia y razonabilidad del propio esquema: el servicio público.

\section{EL DEBATE FINAL: REFORMA O MODERNIZACIÓN PÚBLICA}

Campero (1982), presenta visionariamente desde la generación de su obra, un análisis que trasciende lo semántico, al catalogar la modernización con una tonalidad mucho más amplia y holística que la reforma administrativa. Prescribe el autor lo siguiente:

La conveniencia de adoptar el término modernización administrativa reside en que permite describir con mayor propiedad la clase de cambio que los países desean para sus sistemas administrativos, puesto que por modernización administrativa se entiende el proceso de cambio a través del cual los organismos públicos incorporan nuevas formas de organización, tecnologías físicas y sociales y comportamientos que les permitan alcanzar nuevos objetivos de una manera más adecuada. Visto desde este ángulo, el fenómeno de modernización consiste en un proceso de creación y transformación institucional, a través del cual la administración pública eleva su desempeño para hacer frente a las demandas que sobre ella inciden (p. 20).
Otra fundamentación para potenciar el término "Modernización" y desechar "Reforma", la encontramos en lo indicado en su momento por Beatriz Wahrlich, señalando la autora:

Cabe destacar que no siempre es posible distinguir fácilmente entre reforma administrativa y modernización administrativa. Si trasponemos para el campo administrativo el término "modernización" oriundo de las ciencias sociales (o sea, el proceso por el cual la sociedad incorpora instituciones, formas organizacionales, tecnologías físicas y sociales y comportamientos, que le permitan alcanzar de manera más adecuada objetivos nuevos o renovados), es posible percibir claramente que la modernización administrativa trasciende el ámbito de la tradicional reforma administrativa, preocupada fundamentalmente con la racionalidad y la eficiencia interna de la administración (orientación procesal o instrumental). La modernización administrativa está comprometida con los resultados, con los objetivos que deben ser alcanzados, con los programas y proyectos elaborados para ese fin (1984, p. 36).

Contrario sensu, un detalle trascendental para disipar la duda sobre cuál término sería más adecuado conforme la realidad costarricense, sería preguntarnos: ¿se moderniza para planificar o se planifica para modernizar?

La respuesta se ubica al revalorar lo explicitado en el artículo 16 de la ley 5225, indicándose que, "Los ministerios e instituciones autónomas y semiautónomas llevarán a cabo una labor sistemática de modernización de su organización y procedimientos, a fin de aumentar la eficiencia y productividad de sus actividades y con el propósito de lograr el mejor cumplimiento de los objetivos que persigue el Sistema Nacional de Planificación." 
Precisamente, un argumento a favor del ligamen planificación-modernización lo presenta Eisenstadt (1970), quien acertadamente expone: "La primera característica de la modernización política es un alto grado de diferenciación en los roles e instituciones políticos y el desarrollo de un plan centralizado y unificado, con metas y orientaciones específicas" (p.94). Para el caso particular de Costa Rica, el plan que señala el autor no es otro que el PND instituido en la ley de marras.

Por su parte, Jacome (1975) esboza un argumento que se acopla con el párrafo anterior, indicando que "Un programa de desarrollo o modernización administrativa es una parte de un plan, formada por un conjunto integrado y coordinado de proyectos, que generalmente se aplica en un sector administrativo" (p.64).

Así las cosas, y respetuosos del principio de legalidad establecido para el artículo 11 de nuestra Constitución Política y su homólogo de la LGAP, la modernización pública debe desprenderse de lo diagnosticado, analizado, consensuado, esquematizado y activado en el seno del Sistema Nacional de Planificación instituido en la Ley 5525. Y, con mayor grado de puntualidad, dicho desprendimiento debe enclavarse, primeramente, en el PND del momento, a fin de que sea vinculante para todo el andamiaje institucional cubierto bajo el alero de la dirección gubernativa del Poder Ejecutivo, -tesis defendida a ultranza por Meoño Segura (2008a, 2008b, 2009, 2011 y 2012)-; así analizado y corroborado por la Sala Constitucional mediante diversas Resoluciones: 3309-94, 6345-97 y 2002-12019.

\section{CONCLUSIONES}

Bien puede argüirse que la historia costarricense en materia de propuestas de reforma estatal integral, ha estado marcada por el detrimento en las finanzas públicas (crisis fiscal y afán por contener el gasto público), sin obviar otra serie de condiciones macroeconómicas y externalidades que han potenciado el ánimo por modificar el tono en el cual el aparato estatal ejercía su acción de desarrollo nacional. Por ejemplo, la concepción de un Estado Empresario con CODESA como punta de lanza, se difuminó cuando las constantes pérdidas de ésta fueron asumidas por el Banco Central, el cual ya de por sí hacía como suyas las del Consejo Nacional de Producción $(C N P)$, situaciones que terminan por constituirse en piezas de un mosaico argumentativo sobre el cambio de rol que debía sufrir el Estado en su apartado organizacional. A este mosaico se suman otras piezas como: la necesidad de liberar el monopolio de la Banca Pública sobre los depósitos en cuenta corriente, las desgravaciones arancelarias para potenciar el comercio internacional y ajustarse a los lineamientos de los entes financieros como el Banco Mundial, el nivel exacerbado del gasto público por los régimenes de pensiones con cargo al presupuesto nacional, la modificación del esquema agroexportador vigente, entre otras.

Consideramos que la coyuntura sociopolítica, económica y financiera del país en el periodo 1989-1998, fue sui generis, y resulta imposible replicarla para así lograr una suma de esfuerzos tan prominente que sea capaz de materializar cambios estructurales como lo fueron el cierre de CODESA y el posterior nacimiento de entes como: el Consejo Nacional de Concesiones, la Dirección de apoyo y defensa del consumidor, la Autoridad Reguladora de los Servicios Públicos -antiguo Servicio Nacional de Electricidad-, - la Superintendencia General de Entidades Financieras -antigua Auditoría General de Bancos-. Todos estos son fruto de los proyectos surgidos en el periodo de referencia.

A lo anterior debe sumársele la necesidad de aplacar el aparente gigantismo estatal, considerando que al mismo se le ha achacado la responsabilidad de captar mano de obra para disminuir los niveles de desempleo y aumentar los datos sobre Población Económicamente Activa (PEA), lo 
cual, lógicamente, trae como efecto directo un aumento del gasto público por concepto de remuneraciones y cuotas obrero-patronales; sin que finalmente hubiese capacidad de aquilatar dicho gasto en razón de la efectividad de las instituciones para cristalizar el desarrollo nacional.

$Y$ es que el tema de la reforma administrativa ha sido de interés desde tiempos de la posguerra, tal y como lo evidencian al menos dos de las obras consultadas. Por un lado, el Instituto Centroamericano de Administración Pública (ICAP, 1971), organizó en 1969 el Curso Regional de Reforma Administrativa en el que participaron seis funcionarios de cada uno de los países miembros del instituto, al igual que representantes del Programa de las Naciones Unidas para el Desarrollo (PNUD), del Instituto Nacional de Planificación de Perú, de la Universidad de San Carlos de Guatemala, de la Comisión de Administración Pública de Venezuela, de la Comisión de Administración Pública de México, de la Secretaría de Integración Económica Centroamericana (SIECA), del Banco Centroamericano de Integración Económica (BCIE) y del Banco Interamericano de Desarrollo (BID).

Por otro lado, Wilburg Jiménez (2006), se refiere a un ingente número de propuestas de reforma, entre las que menciona la Conferencia de Macroreforma Administrativa en Brigthon, Gran Bretaña, auspiciada por las Naciones Unidas y la Universidad de Sussex en 1971.

Obsérvese que la necesidad de replantear constantemente el tema aquí tratado no es nada nuevo, y dudamos que deje de ser de interés por parte de los cuadros políticos y técnicos (funcionarios de carrera) insertos en la administración pública, en la arena política (partidos políticos), o en las universidades (institutos de investigación, directores de carrera, docentes y estudiantes).

Por ende, el abordaje que se ha tratado de lograr en el presente ensayo presentó, en forma sucinta, consideraciones antecedentales, teóricas, conceptuales y jurídicas propias de la reforma en
Costa Rica desde una perspectiva pragmática y funcional. Esto, valorando que un ensayo de este tipo que se decante por lo meramente histórico no genera mayor valor, por cuanto el lector interesado podrá acceder a copiosa bibliografía al respecto, y caeríamos así en una repetición fútil de elementos investigativos estériles para la mejor comprensión de la reforma en nuestro contexto.

Tenemos claridad, por lo arriba expuesto, que las intenciones y esfuerzos de reforma se activarán, potenciarán o decaerán en razón de las orientaciones doctrinario-filosóficas del ápice gubernativo de turno. Y que tales esfuerzos son posibles con fundamento en el marco normativo vigente, correspondiéndole a los técnicos y especialistas propios de la Administración Pública -del MIDEPLAN, particularmente- la correcta guía a los actores políticos al respecto, evitando que estos últimos propongan o esquematicen planteamientos falaces y carentes de racionalidad y viabilidad de todo tipo: jurídica, financiera, o ircluso terminológica.

\section{REFERENCIAS}

Aguilar, J. (2008). El marco referencial de la economía pública. Revista de Ciencias Económicas, 26 (2), 197-214.

Araya, C. (2006). Historia de América en perspectiva Latinoamericana. San José: EUNED.

Bolaños, R. (2010a). Un abordaje teórico, jurídico y conceptual de los términos reorganización y reestructuración administrativa en Costa Rica. Revista Nacional de Administración 1 (1), 147-156.

Bolaños, R. (2010b). Algunas consideraciones teóricojurídicas para el diseño organizacional en la Administración Central costarricense. Revista Centroamericana de Administración Pública (58-59), 305-329.

Campero, G. (1982). La reforma administrativa en América Latina. México: INAP. 
Centro Latinoamericano de Administración para el Desarrollo. (1998). Nueva Gestión Pública para América Latina. Caracas: Autor.

Cervantes, R. (2000). Reforma del Estado: una vía en procura de la huida del Derecho Administrativo, particularmente en materia de contratación administrativa. Revista de Ciencias Jurídicas 91 (enero-abril), 33-20.

Comisión de Reforma del Estado Costarricense (COREC). (1990). Reforma del Estado en Costa Rica. San José: Impreso por EDICOSTA.

Cunill, N. (1999). ¿Mercantilismo y neo-clientelismo o reconstrucción de la Administración Pública? Retos de las reformas de segunda generación. Nueva Sociedad 160 (marzo-abril), 101-117.

De la Cruz, Y., Li Chen, S., Morales, M. y Zamora, C. (s.f). El programa de ajuste estructural: salud y pobreza. Revista costarricense de salud pública 4 (6), 25-41.

Eisenstadt, S.N. (1970). Burocracia y desarrollo político. En LaPalombara et al. Burocracia y desarrollo político (pp.92-112). Buenos Aires: Paidos.

Fallas, H. (1982). Crisis económica en Costa Rica. Un análisis económico de los últimos 20 años. San José: Nueva Década.

Filgueira, F. y Martínez, J. (1998). Paradigmas globales y filtros domésticos: reforma administrativa y política social en América Latina. Revista de Ciencias Económicas 18 (2), 191-215.

Fonseca, L. (2001). La regulación de los servicios públicos como garantía para los habitantes. En Sánchez, R. (Ed). Derecho constitucional y administrativo (pp.79-107). San José: Oficina de Publicaciones de la Universidad de Costa Rica.

Guerrero, O. (2010). La administración pública a través de las ciencias sociales. México: Fondo de Cultura Económica.

Harrison, L., Lizano, E., Urcuyo, C. y Camacho, E. (1994). Evaluation of the USAID in Costa Rica's Public Sector Reform (Reforma del Estado) Program. Recuperado de: pdf.usaid.gov/pdf_docs/Xdabj291a.pdf
Hidalgo, R. (2008). Apuntes sobre el servicio público en tiempos de globalización. Revista de Ciencias Jurídicas 116 (mayo-agosto), 33-20.

ICAP. (1971). Reforma administrativa. Documentos de un seminario. San José: ICAP.

Jiménez, W. (2006). La reforma administrativa, la reforma del estado y la privatización de instituciones, empresas y programas públicos. San José: EUNED.

Jiménez, W. (1986). Génesis del Gobierno de Costa Rica. - Vol. Il -. San José: Alma Mater.

Jinesta. E. (2002). Tratado de Derecho Administrativo. Tomo I (Parte General). San José: Biblioteca Jurídica DIKE.

Jacome, M.J. (1975). La planificación administrativa para el desarrollo económico y social en América Latina. En Kliksberg, B. y Madrid, P.J. (Comp.). Aportes para una administración pública latinoamericana (pp. 63-114). Caracas: Universidad Central de Venezuela.

Leemans, A.F. (1977). Cómo reformar la administración Pública. México: Fondo de Cultura Económica.

Lizano, E. (1987). Desde el Banco Central. San José: Academia de Centroamérica.

Martner, G. (1975). El papel de la reforma administrativa en la estrategia del desarrollo. En Kliksberg, B. y Madrid, P.J. (Comp.). Aportes para una administración pública latinoamericana (pp.171-182). Caracas: Universidad Central de Venezuela.

Meoño, J. (2012). Análisis de los procesos de dirección, planificación gubernativa, políticas públicas y reforma del Estado en Costa Rica. Revista de Ciencias Económicas, 30 (1), 13-72.

Meoño, J. (2011). Planificación del Desarrollo en Costa Rica. Lecciones de la experiencia. San José: Escuela de Ciencias Políticas, Universidad de Costa Rica.

Meoño, J. (2009). Modelo-País de largo plazo: los derechos constitucionales de los habitantes. San José: IICE/UCR.

Meoño, J. (2008a). Guía para un excelente Gobierno y para un ciudadano menos indolente. San José: IICE/UCR. 
Meoño, J. (2008b). El Modelo-País en la Constitución Política y en unas pocas leyes superiores: marco referencial ineludible para lograr una mejor investigación académica y un real desarrollo nacional. San José: IICE/UCR.

Meoño, J. (2005). Exigencia y rendición de cuentas sobre ingreso y gasto público: un análisis de lo que jurídica, institucional y políticamente puede hacerse en la materia. San José: IICE/UCR.

Meoño, J. (1988). Teorías administrativas en América Latina (Perspectivas Críticas). San José: Guayacán.

Meoño, J. (1986). Administración Pública: Teoría y Práctica.-2 edición.- San José: EUCR.

Meoño, J. (1980). Introducción al análisis de la burocracia pública. San José: EUCR.

Naranjo, G. (2010). Instituciones político-económicas de Costa Rica. San José: EUNED.

Osborne, D. y Plastrik, P. (1998). La reducción de la burocracia. Cinco estrategias para reinventar el gobierno. Barcelona: Paidós.

Osborne, D. y Gaebler, T. (1994). Un nuevo modelo de gobierno: cómo transformar el espíritu empresarial al sector público. México: Gernika.

Oszlak, O. 1999. De menor a mejor. El desafío de la segunda reforma del Estado. Nueva Sociedad, 160 (marzo-abril), 81-100.

Pérez, H. (2002). Breve historia contemporánea de Costa Rica. México: Fondo de Cultura Económica.

PNUD/FLACSO. (2005). Desafíos de la democracia: una propuesta para Costa Rica. San José: Autor.

Quesada, R. (2008). Ideas económicas en Costa Rica (1850-2005). San José: EUNED.
Rodríguez, M.A. (1985). El orden jurídico de la libertad. San José: VERBVM.

Rojas, M. (1987). Ocho tesis sobre la realidad nacional. En Torres, E. et al. Costa Rica: crisis y desafíos (pp.15-28). San José: DEl.

Romero, J.E. (2010). Derecho administrativo general. San José: EUNED.

Romero, J.E. (1983). El servicio público. San José: Publicaciones de la Facultad de Derecho - Universidad de Costa Rica.

Vestre Piam, S. (1994). El Estado y la competitividad de la economía. En Kliksberg, B. (Comp.). El rediseño del Estado. Una perspectiva internacional. México: INAP/Fondo de Cultura Económica.

Stein, S. y Stein, B. (1974). La herencia colonial de América Latina. - 7ma edición -. México: Siglo XXI.

Universidad de Costa Rica. (1996). A la búsqueda del Siglo XXI: nuevos cambios de desarrollo en Costa Rica. San José: EUCR.

Villasuso, J.M. (2000). Reformas estructurales y política económica en Costa Rica. Serie Reformas Económicas 64. Santiago: CEPAL.

Wahrlich, B. (1984). Evolución de las ciencias administrativas en América Latina. En Flores, G. y Nef, J. (Comp.) Administración Pública: perspectivas críticas. San José: ICAP.

Zúñiga. C. (2001). El Estado y los habitantes ¿una dicotonomía? En Sánchez, R. (Ed). Derecho constitucional y administrativo (pp.14-46). San José: Oficina de Publicaciones de la Universidad de Costa Rica.
Recibido: 19 de enero de 2016 Aceptado: 3 de abril de 2016 
This document was created with Win2PDF available at http://www.win2pdf.com. The unregistered version of Win2PDF is for evaluation or non-commercial use only. This page will not be added after purchasing Win2PDF. 